\title{
THE AROUSAL OF INGESTIVE BEHAVIORS BY CHEMICAL INJECTION INTO THE BRAIN OF THE SUCKLING RAT ${ }^{1}$
}

\author{
SUSAN ELLIS, KAREN $\Lambda$ XT, AND $\Lambda L \Lambda N$ N. EPSTEIN ${ }^{2}$ \\ Department of Biology, University of Pennsylvania, Philadelphia, Pennsylvania 19104
}

Received June 27, 1983; Revised October 31, 1983; Accepted November 2, 1983

\begin{abstract}
Three neurochemical agents known to arouse ingestion in adult rats were studied in milk-sated rat neonates ingesting fluids away from their dams. All were given intracerebroventricular (ICV) injection. Drinking of both milk and water by 2-day-olds injected with angiotensin II (Ang II) was confirmed. The characteristic adult dipsogenic response, intake of water greater than that of milk, appeared at 8 days. ICV carbachol (Carb), on the other hand, did not elicit drinking before 4 days, despite the fact that these dipsogens (Carb and Ang II) may both affect receptors in the subfornical organ.

ICV norepinephrine (NE) increased milk intake beginning at 9 to 10 days, which coincides with the age at which central adrenergic receptors believed to mediate NE's orexigenic effect are appearing in the developing forebrain. NE had no effect on water intake at any age.

The effects of all three agents on ingestive behaviors were dose-dependent.

These data suggest that the neural systems utilized by Ang II, Carb, and NE are competent for mediation of specific ingestive behaviors before they reach full anatomical and biochemical maturity.

Last, NE did not increase milk intake of pups suckling from their dam at any age. The noradrenergic system that is developing in the rat brain during the suckling period appears to be a nascent control of subsequent adult feeding rather than a functioning control of ongoing suckling.
\end{abstract}

The infant rat pup fulfills its needs for both food and water with the milk it receives by sucking its mother's teat. Not until weaning, which begins at 15 days (Babicky et al., 1973) and may not be complete until 30 days, does it spontaneously emit adult ingestive behaviors that allow it to satisfy hunger and thirst with separate substances. Nevertheless, it is now well established that preweanling rats will drink water in response to several thirst challenges and that they do so in an adult-like manner.

Almli (1973) offered rat pups lying in a warmed litter the opportunity to lick water from a dropper held at their lips and showed that 14-day-olds are capable of drinking water promptly and avidly in response to cell dehydration. Wirth and Epstein (1976) then found that when permitted to lick at a "water fountain" rat pups would drink water in response to cell dehydration at 2 days, hypovolemia at 4 days, and $\beta$-adrenergic activation at 6 days of age. The pups did not suck the water. Instead, they lapped and swallowed it in a surprisingly mature fashion. Recently, Bruno (1981) not only confirmed

\footnotetext{
${ }^{1}$ This work was supported by National Institutes of Health Grant NS 03469 to A. N. E. S. E. was a fellow of Institutional Training Grants MH 15092 and GMS 5517.

${ }^{2}$ To whom correspondence should be addressed.
}

Wirth and Epstein's (1976) report of the precociousness of the rat's response to cell dehydration, but they also demonstrated that a 3-day-old pup would lick fluids (water or milk) off the floor of its container (as well as consume fluids infused directly into its mouth) in response to this challenge. Furthermore, he found that by the middle of its second week of life, the dehydrated pup approached fluids and drank them from a distant source. Lastly, using the technique of Wirth and Epstein, Misantone et al. (1980) demonstrated the responsiveness of 2- to 4-day-old rats to the dipsogenic actions of intracranial angiotensin II (Ang II).

Although the controls of independent feeding have not been as thoroughly explored as those of drinking, Raskin and Campbell (1981) have demonstrated that the anorexia produced by amphetamine in the adult rat is also produced in 5-day-old pups when milk is offered to them while they are off the nipple.

These data suggest that in the interval between birth and weaning, when the animal is expressing only suckling behavior, the neurological mechanisms for adult feeding and drinking are reaching maturity. In the following experiments, we have explored this idea further by studying the development of the responsiveness of the neonatal brain to three agents that have powerful and specific effects on ingestive behavior in the adult rat. We 
have re-examined the developmental calendar for the dipsogenic response to intracranial angiotensin II and have investigated the infant rat's response to intracranial carbachol (Carb) and norepinephrine (NE).

The following questions have been asked of all three agents: (1) At what developmental age does the rat brain become responsive to the agent of interest as expressed by changes in the pup's ingestive hehavior? (2) At what age does it achieve adult sensitivity as shown by a doseresponse curve? (3) At what age does the response become that which is characteristic of the adult? (4) What relations can be discerned between the behavioral competence of the pup and developing neurological system?

In doing so, we have been sensitive to the possibility that suckling may not be a mere developmental precursor to or simply an immature form of adult ingestion. Rather, we have accepted the idea that it may be an autonomous ingestive behavior with a developmental course and set of controls of its own (Hall, 1979; Blass and Cramer, 1982). Therefore, the effects of norepinephrine on ingestion by isolated pups that are off the dam, in imitation of adult feeding or drinking, have been compared to the effects of the agent on the ingestion of pups that are suckling in a natural litter.

\section{Materials and Methods}

\section{Methods for testing pups off the dam}

Subjects. Rat pups that were born into litters conceived in our laboratory by primiparous and multiparous Holtzman albino rats were used. In the week before giving birth, pregnant females were moved to individual breeding bins containing cedar-chip bedding. Water and Purina pellets were freely available. The nursery was kept on a $14: 10 \mathrm{hr}$ day/night cycle. Mothers were checked for births each afternoon at 5 P.M., and pups found at that time were designated as 0 days of age. Between 2 and 4 days after birth, litters were culled to 10 pups; further handling was minimized by changing the bedding only once every 10 days.

Procedure. On the morning of the experiment, eight pups from each litter to be tested were removed from their mother and implanted with an anterior oral catheter as described by Hall (1979). The catheter is fashioned from a $7-\mathrm{cm}$ piece of PE-10 tubing, heat flanged at one end and friction-fitted over a fine piano wire at the other. The wire is inserted through the mouth into the soft tissue just behind the root of the lower incisors and in front of the base of the tongue. The insertion was quickly accomplished and was, in most instances, bloodless. Anesthesia was not necessary. With the catheter in this anterior position, fluid infusions spill out of the pups' mouth unless they are actively ingested.

Pre-injection treatments. 'The pups' anogenital area was covered with celloidin ( $12 \%$ in ether-alcohol) to prevent spontaneous excretion. They were then weighed to the nearest $0.01 \mathrm{gm}$ (Precisa balance) and transferred to a glass-front incubator kept at 32 to $33^{\circ} \mathrm{C}$. The inlet of the mouth catheter was connected to an infusion lead consisting of PE-50 tubing attached to a $10-\mathrm{ml}$ syringe mounted on a Harvard infusion pump which delivered 15-sec pulses of milk (Borden's Half \& Half) or water every $2 \mathrm{~min}$. The milk used has certain similarities to rat's milk (e.g., percentage of fat and water), although it is not an adequate diet for normal growth.

The pups were reweighed at 20 -min intervals or until weight gain, a valid measure of intake (Houpt and Epstein, 1973), leveled off, typically after three, $20 \mathrm{~min}$ sessions. The pump was calibrated to deliver a total infusate volume equal to $5 \%$ of the body weight (bw) of the average pup tested at that age in any 20 -min session, a volume which was slightly greater than they could consume. This assured complete satiation. Hereafter, this will be referred to as the pre-injection ingestion period.

Having reached an asymptote of intake indicative of satiation, the pups were removed from the incubator and given a $1-\mu \mathrm{l}$ intracranial injection of either $2 \mu \mathrm{g}$ of NE (1-norepinephrine bitartrate, Calbiochem), $100 \mathrm{ng}$ of Ang II (Asp ${ }^{1}$-Ile ${ }^{5}$-Ang II, Sigma), or $100 \mathrm{ng}$ of Carb (carbamylcholine chloride, Sigma) dissolved in a vehicle of $50 \%$ India ink and $50 \% 0.15 \mathrm{M} \mathrm{NaCl}$, or a $1-\mu \mathrm{l}$ injection of the vehicle alone. The doses are all well above threshold for effects on ingestive behavior in adult rats.

Intracranial injection. The NE, Ang II, or Carb was delivered intracranially by piercing the scalp and cartilaginous skull of the unanesthetized pup with a 23 gauge guide cannula to a depth of $2 \mathrm{~mm}$ into the brain at a point approximately $1 \mathrm{~mm}$ to the right of the sagittal suture and $2 \mathrm{~mm}$ posterior to bregma (which are visible through the pup's translucent scalp). A concentric 27 gauge injection cannula was then extended to a final depth of 4 to $6 \mathrm{~mm}$ (depending on the age of the pup), permitting the delivery of Ang II or Carb into the lateral and dorsal third ventricles, or to $7 \mathrm{~mm}$, permitting deposition of the NE into the ventral third ventricle. Because our intent was injection into the cerebral ventricles, the injections are referred to as intracerebroventricular (ICV). The ICV procedure required less than $15 \mathrm{sec}$. It seemed to produce no discomfort and did not interfere with the animals' behavioral competence (see Misantone et al., 1980 for original description). Again, the pups were not anesthetized since an anesthetic, such as ether, causes greater distress than the intracranial injection (cf. Hall, 1979). In addition, avoidance of the artifacts of anesthesia allowed the study of ingestive behaviors immediately after the intracranial injections. The pups were replaced in the incubator after the injections were made, and the infusion regime (as described above) was continued for $30 \mathrm{~min}$. They were now reweighed after each 10 min ingestion period. This is referred to hereafter as the postinjection ingestion period. Except for the short times required for weighings and injections, pups were kept throughout the experiment in clear, Plexiglas containers inside the incubator.

Verification of injection site. After the final weighing, animals were decapitated, and the site of injection was determined by examination of the surface of a coronal section through the head as shown in Figure 1. The section was made at the anterior-posterior level of the scalp wound with a hand-held single-edged razor blade. For Ang II and Carb, the lateral ventricle was designated as the site of a successful injection. For NE, the third 


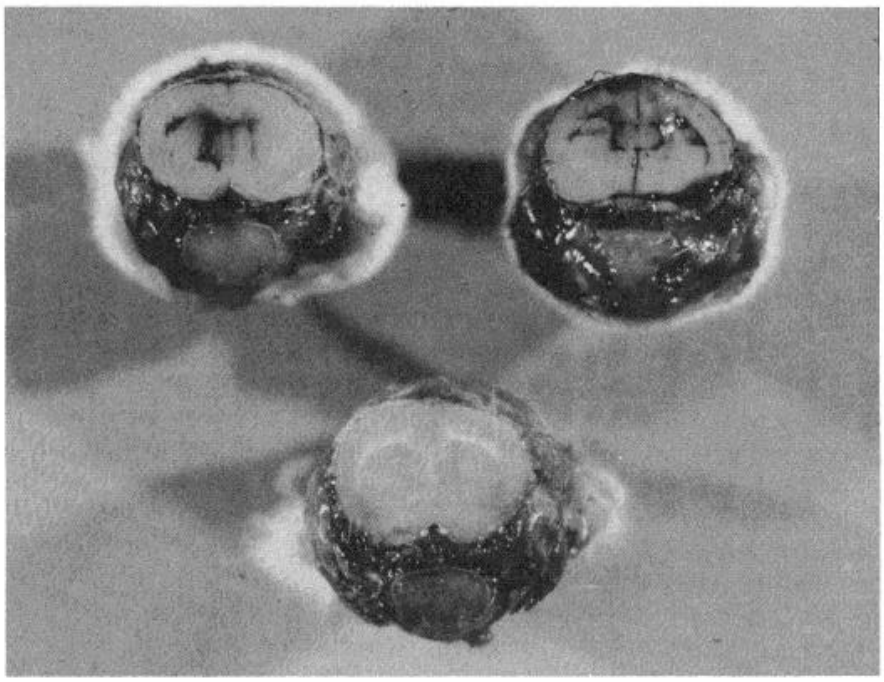

Figure 1. Confirmation of ICV injection. Successful injection (upper right) with India ink is clearly visible in the anterior cerebral ventricles. Compare with India ink (upper left) delivered into brain parenchyma in unsuccessful injection and with uninjected brain (below). Photographs are of fresh autopsy material, no fixation or stains.

ventricle was chosen since the paraventricular nucleus, a butterfly-shaped nucleus which lies on either side of the ventral third ventricle, is sensitive to adrenergic activation of feeding (Leibowitz, 1978).

Selection of subjects and statistics. Litters were treated as the experimental unit throughout these experiments. A litter was tested at one age only with pups from one litter serving in a given experimental condition. Vehicle and neurochemically injected rats were chosen without regard to the volume of milk or water that they had ingested in the pre-injection ingestion period. Data were analyzed by an analysis of variance of each experiment, and individual comparisons were made using the Neuman-Kuels Test.

\section{Methods for testing sucklings on the dam}

\section{Subjects}

These were the same as described under "Methods for Testing Pups off the Dam.”

\section{Procedure}

Preparation of the dam. At approximately 4 P.M. on the day preceding the experiment, the mother of the test litter and 2 of her 10 pups were removed from the nursery bin and placed in a transparent test bin. They remained there for approximately $1 \mathrm{hr}$ so that she could adapt to nursing in the novel environment. The test bin rested on a transparent glass shelf over a mirror at an angle of approximately $45^{\circ}$ facing forward. This permitted a view of the dorsal, lateral, and ventral surface of the dam and her suckling pups. To facilitate observation, no bedding was placed in the test box. When the experimenter noted that the dam was comfortably and quietly suckling her young, she and her two pups were replaced into her original breeding bin.
Preparation of the test litter. Meanwhile, the remaining eight pups of her litter were placed with a lactating foster dam. This exchange was necessary to ensure that the test dam had an adequate milk supply for the experiment to be carried out on the following day. In the case of the deprivation experiment, the remainder of the litter was placed in a Plexiglas container lined with paper towels and put into a glass-front incubator $\left(32\right.$ to $\left.33^{\circ} \mathrm{C}\right)$ in the absence of a dam. This procedure was also used for the experiment where animals were milk-sated before suckling. In this case, the pups, who were deprived of both their mother and her milk the night before the experiment ( 12 to $14 \mathrm{hr}$ ), were then fed milk prior to injection (described above as the pre-injection ingestion period).

Reunion and testing. On the next morning, the test dam was returned to the test bin, this time without pups, in order to readapt to the test environment. When the experimenter noted that she was resting quietly, usually after 60 to $90 \mathrm{~min}$, her eight pups were removed from the foster dam and prepared for an intracranial injection of either $100 \mathrm{ng}$ of Ang II, $2 \mu \mathrm{g}$ of NE, or $1 \mu \mathrm{l}$ of vehicle. The injections were made as described above, with half of the pups receiving the neurochemical agent to be tested on that day and half receiving the vehicle. The pups were then numbered on their backs and stomachs with a marking pen, weighed to the nearest $0.01 \mathrm{gm}$, placed in the test bin with their mother, and allowed to suckle.

Behavioral observations. After the pups were placed with their mother in the test box, the initial latency of their reattachment to a nipple was recorded in minutes and seconds as described by Lorenz et al. (1982). Typically, the mother retrieved the pups, groomed them, then licked her ventral surface, including both nipple lines. The pups were stimulated by the maternal behavior and rooted in the mother's fur until contact was made with a nipple. They sniffed the area and occasionally licked the nipple. Attachment was recorded only if the pup drew a nipple deep into its mouth and closed its lips around its base.

Incidence of attachment. Since in the natural suckling situation the pups cannot consume milk unless attached to a nipple, it was necessary to quantify attachment behavior throughout the test (Lorenz et al., 1982). This was achieved by recording the number of pups attached every 5 min throughout the 2 -hr refeeding period in a 15 -sec period of observation and is referred to as the incidence of attachment.

Volume of milk ingested. Since weight gain is a valid measure of intake (see above), the amount of milk consumed by each pup was calculated as the difference between the weight of each pup at the end of a 1-hr suckling bout and its weight just after the injection was made. Injection placements were verified as described above.

\section{Experimental procedures}

\section{Experiment I: Development of ingestive behaviors}

Subjects and procedure. Zero to 13-day-old pups, from litters conceived and born in our breeding colony, were used. In each litter tested, four pups received an injection 
of the neurochemical agent and four received a vehicle injection.

As discussed below, the data from the pre-injection ingestion period (see Fig. 6) indicate that pups taken directly from their dams can ingest large volumes of milk when it is offered through an oral catheter. Therefore, all pups were offered milk during this period to ensure that they were equally sated and to prevent their large spontaneous intake from obscuring the effects of the agent in the postinjection ingestion period.

\section{Experiment II: Dose-response relationships}

Subjects and procedure. Pups of 6 to 8 and 10 to 12 days of age were used to determine the dose-response relationships of Carb and NE, respectively. (Ang II was studied in an earlier experiment (Misantone et al., 1980).) The results of experiment I demonstrate that the effects of these agents on ingestive behavior are well established at the ages chosen.

For the reasons given in experiment I, all pups in this experiment were sated on milk during the pre-injection ingestion period. Again, carb-injected pups were offered water postinjection, and those injected with $\mathrm{NE}$ were given milk.

Injection procedures were the same as in the preceding developmental work, except that $0.15 \mathrm{M} \mathrm{NaCl}$ was used as a vehicle to eliminate the possible absorption of the agents onto the surface of the carbon in the India ink vehicle at the lower doses. We felt confident of injecting without a marker since the accuracy of placement in experiment I was appoximately $95 \%$.

Dose of NE was varied over three orders of magnitude $(0.02 \mu \mathrm{g}$ to $2 \mu \mathrm{g})$, and that of Carb was varied over four orders $(0.1 \mathrm{ng}$ to $100 \mathrm{ng})$. All doses were administered in $1 \mu \mathrm{l}$ of the vehicle. Within each litter, two doses of the same neurochemical agent were tested, four pups receiving the agent and four receiving the vehicle.

\section{Experiment III: Development of adult responses}

Subjects. Pups, ages 2 to 13 days, were chosen for the Ang II condition, since results from experiment I show that Ang II does not effect water intake in pups younger than 2 days. For the NE condition, 11- to 13-day-old pups were used because NE does not effect milk consumption until 9 days postpartum.

Procedure. There were two pre-injection conditions. In the first, eight pups in the litter were milk-sated before being injected. The litter was then divided into four groups: (1) two animals received ICV injection of agent and were offered milk; (2) two animals received ICV injection of vehicle and were offered milk; (3) two animals received ICV injection of agent and were offered water; and (4) two animals received $\mathrm{ICV}$ injection of vehicle and were offered water. In the second condition, the postinjection regime was the same but the pups were water-sated rather than milk-sated during the pre-injection ingestion period. This allowed us to ask: Does the type of fluid offered before injection influence the differential effect on intake of the neurochemical agent? For example, does a hydrated pup consume the same amount of milk after an injection of NE as does a milk-sated pup?
To answer the major question of this experimentwhen does the adult-like response to this neurochemical agent first appear in the infant? - the paradigm outlined above was repeated in pups of various ages, beginning with the age at which the ingestive response to the agent first appeared, e.g., 2 days for Ang II and 10 days for NE.

\section{Experiment IV: Effects of ICV NE}

The procedure was as described above under "Methods for Testing Sucklings on the Dam."

\section{Results}

\section{Experiment I: Development of ingestive response to $I C V$} Ang II, Carb, and NE

This experiment reveals the age at which the rat first responds, by changes in ingestive behavior, to intracranial injections of Ang II, Carb, and NE. Since both Ang II and Carb are dipsogenic in the adult rat, pups in this part of the experiment were offered water during the postinjection ingestion period. NE arouses feeding in the adult (Grossman, 1960). Therefore, pups in this portion of the experiment were offered milk during the postinjection ingestion period in order to assess the age at which NE increases the consumption of the neonate's natural food, i.e., milk. All pups were offered milk in the pre-injection ingestion period.

Ang II. Analysis of weight gain across all ages tested showed that Ang II-treated rats drank more than vehicle controls (Ang II main effect: $F(1,138)=184.00, p<$ $0.0001)$. As is shown in Figure 2, by 2 days of age animals receiving $100 \mathrm{ng}$ of Ang II ICV drink two to three times more water than their littermate controls (Fig. 2; hor-

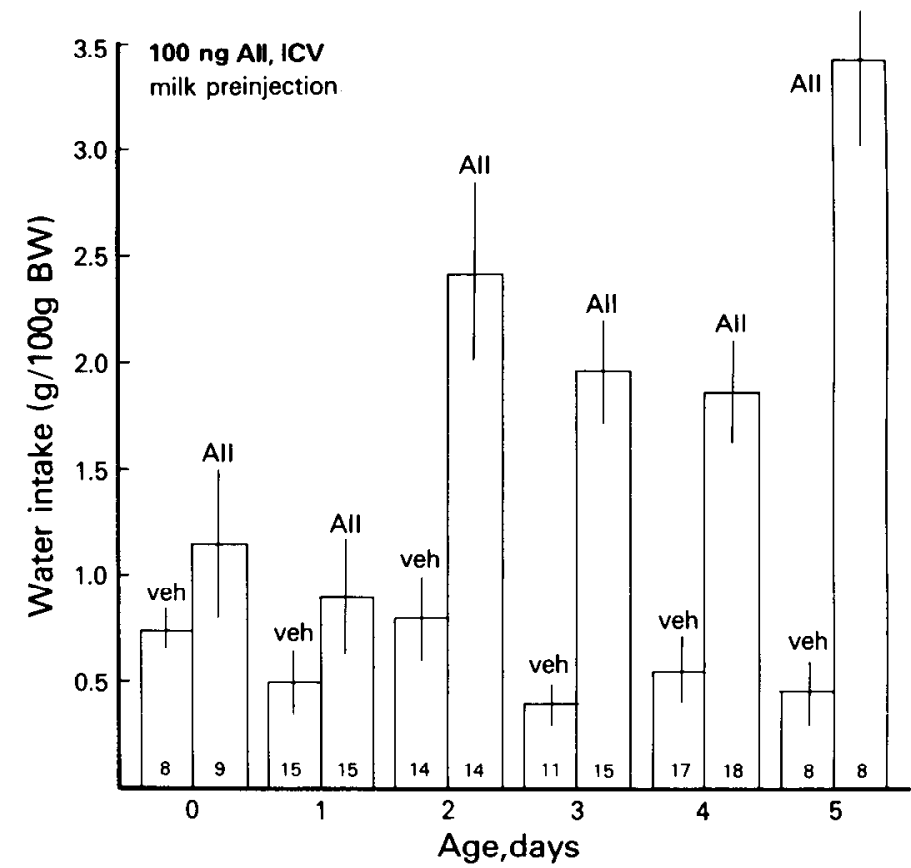

Figure 2. Development of Ang II-induced drinking. By 2 days of age milk-sated pups drink water in response to ICV Ang II. There is a further increase in responsiveness at 5 days. In this and subsequent figures numbers within bars are animals tested at each age, and open bars denote pups given water in the postinjection ingestion period. 


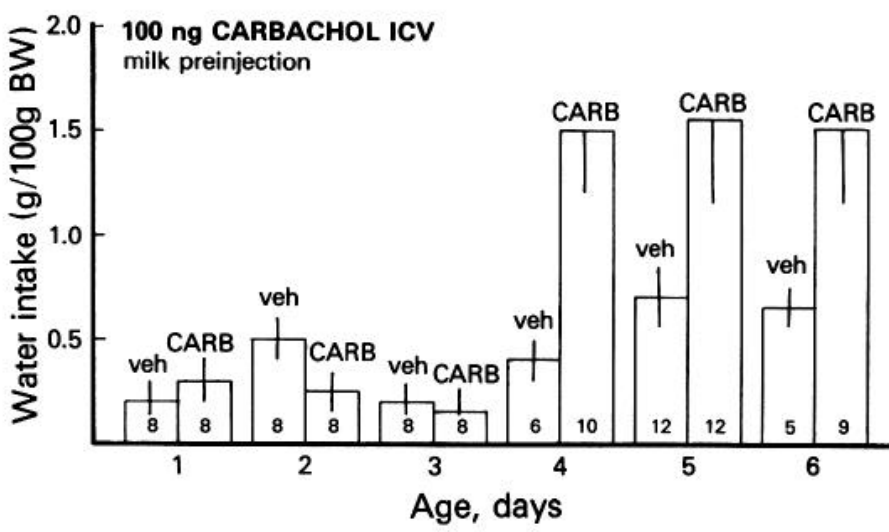

Figure 3. Development of carbachol-induced drinking. Milksated pups do not drink water in response to ICV Carb until 4 days.

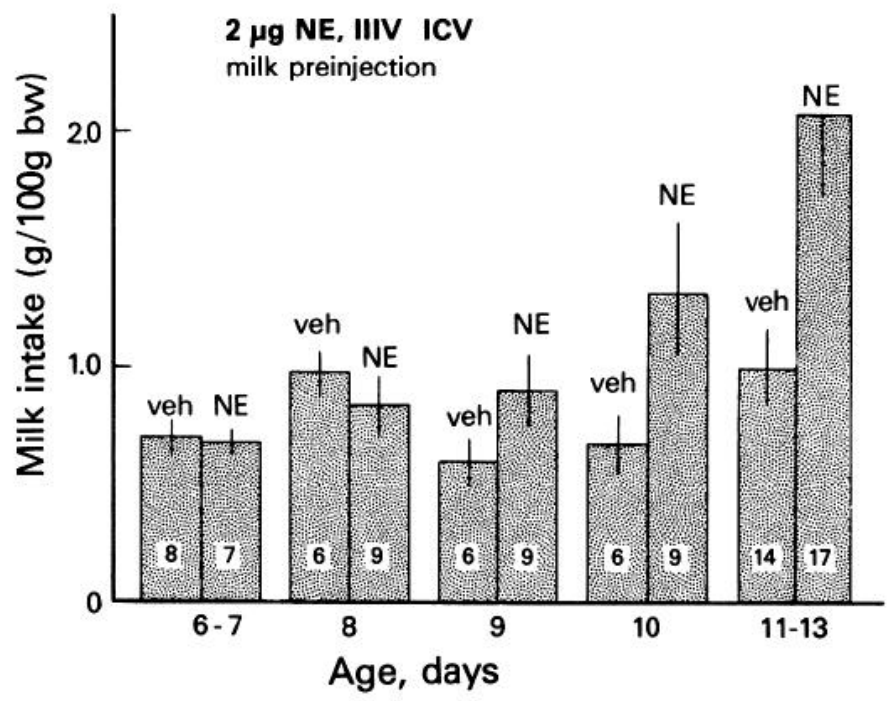

Figure 4. Development of NE-induced feeding. By 10 days ICV NE increases milk intake in the milk-sated pup. In this and subsequent figures, stippled bars denote pups given milk in the postinjection ingestion period.

mone $\times$ day interaction $F(6,138)=11.27, p<0.0001)$. This trend continues until 5 to 6 days postpartum, when Ang II causes a second, even greater increase in water drinking (Neuman-Kuels, $p<0.05$ ). Our analysis also revealed that 2-day-old, Ang II-injected pups drink as much water as 5-day-olds but less than 6-day-olds (Neuman-Kuels, $p<0.05$ ).

Carb. In contrast to Ang II, the dipsogenic effects of $100 \mathrm{ng}$ of ICV Carb are first manifest at 4 days of age (Fig. 3; Carb main effect: $F(1,90)=12.97, p<0.0005$; hormone $\times$ day interaction: $F(5,90)=3.31, p<0.01$; Neuman-Kuels, $p<0.05$ ) at which point intake reaches a plateau, with no further augmentation occurring at later ages.

$N E$. Figure 4 depicts the milk intake of pups after they were injected with $2 \mu \mathrm{g}$ of $\mathrm{NE}$ into the third ventricle. Not until 9 to 10 days of age do pups consume more milk than their littermate controls. (NE main effect: $F(1,70)$ $=9.10, p<0.004)$.
The receptors for NE's effect on food intake in the adult rat appear to reside within the paraventricular nuclei (Leibowitz, 1978) which are adjacent to the ventral third ventricle. To test their mediation of the orexigenic response to $\mathrm{NE}$ in pups, we compared the milk intakes of the following groups of 11-day-olds: (1) vehicle-injected animals; and, as a result of postmortem examination, (2) animals in which NE was successfully deposited into the third ventricle ( $\mathrm{NE}$ inside third ventricle), and (3) animals in which NE was deposited elsewhere in the brain or into the subarachnoid space beneath the brain (NE outside third ventricle). The results are shown in Figure 5. Clearly, only when NE was deposited into the third ventricle was milk drinking augmented.

\section{Experiment II: Dose-response relationships}

As is evident from Figure 6, there is a dose-dependent relationship between Carb and water drinking (dose main effect: $F(4,36)=6.08, p<0.001)$ as well as between $\mathrm{NE}$ and milk drinking (dose main effect: $F(4,36)=3.49, p<$ 0.02 ). Comparisons between the highest and lowest dose of each agent ( $100 \mathrm{ng}$ versus $0.1 \mathrm{ng}$ of Carb; $2 \mu \mathrm{g}$ versus $0.2 \mu \mathrm{g}$ of NE) are significant (Neuman-Kuels, $p<0.05$ ).

\section{Experiment III: Development of characteristic adult responses to $N E$ and Ang II}

Ang II is dipsogenic in the adult rat, and NE affects only feeding, e.g., is orexigenic. This experiment was designed to discover when these agents produce their characteristic adult-like effects on ingestive behaviors in the rat pup. Consequently, both Ang II- and NE-injected

\section{Response to $2 \mu \mathrm{g}$ Norepinephrine ICV at 11-13 days}

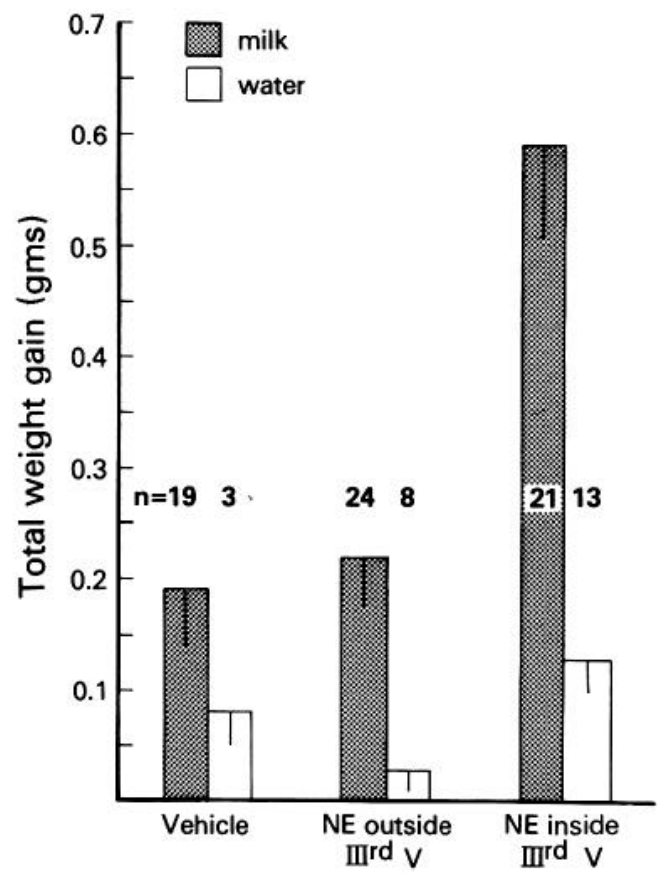

Figure 5. ICV NE has its orexigenic effect only when it is deposited in the third ventricle. Water intake remains low under all conditions. 

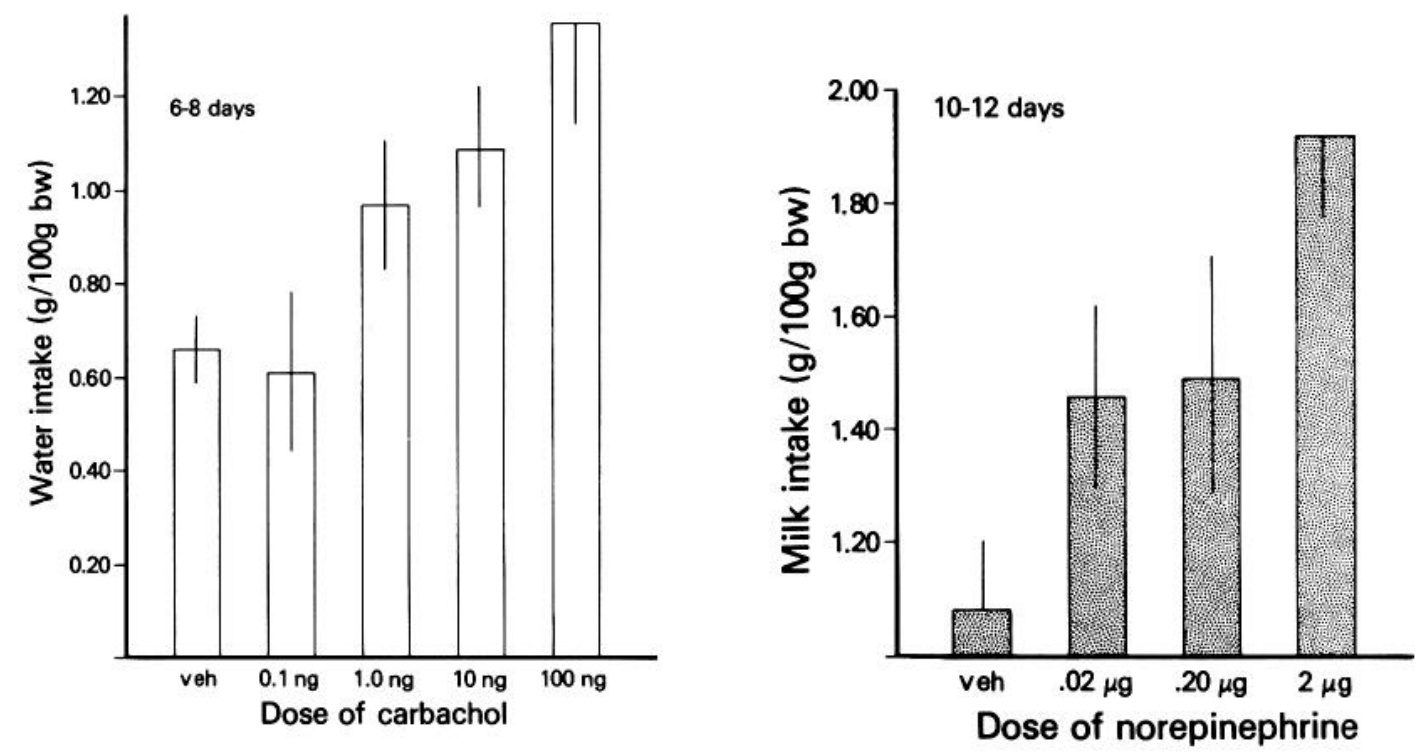

Figure 6. Left, Carb causes a dose-dependent increase in water drinking in 6- to 8-day-olds. Right, NE increases milk drinking in a dose-dependent manner in 10- to 12-day-olds.

pups were offered the opportunity to ingest either milk or water.

In this experiment the fluid offered in the pre-injection period becomes particularly important because the ingesta consumed prior to injection might influence its subsequent intake. This was suggested by the data, shown in Figure 7, which demonstrate that, although pups younger than 9 days of age consume approximately equal amounts of milk or water during the pre-injection period, milk consumption rises abruptly after that age. The pups are, therefore, exhibiting a kind of "neonatal gluttony." By day 15 , they are drinking close to $6 \%$ of their body weight in milk in less than an hour. As a result, we included two pre-injection conditions in this experiment: (1) pups received milk prior to injection with Ang II or NE and (2) pups received water prior to injection with Ang II or NE. We then compared the effects of both of these neurochemical agents on the ingestion of milk or water.

$N E$. It is evident from the right panels of Figure 8 that no matter which fluid the pup is offered prior to ICV injection, $\mathrm{NE}$ is only orexigenic; it never enhances water intake. Therefore, from the day it first effects ingestion (9 to 10 days) NE displays its characteristic adult-like effect on food intake alone (hormone main effect: $F(3,34)$ $=12.69, p<0.0001$; Neuman-Kuels, $p<0.05$.

Ang II. In contrast to NE, the left panels of Figure 8 show that Ang II is effective in augmenting the intakes of both milk and water in 8- to 11-day-old pups (postinjection main effect: $F(1,34)=58.73, p<0.001$; NeumanKuels, $p<0.05$ ). However, when they are milk-sated prior to injection, pups drink twice as much water as milk, which is indicative of the adult response to Ang II. Figure 9 demonstrates that this differential dipsogenic effect of Ang II is not manifest in the milk-sated pup until 8 days of age. Before that time, pups drink the same amount of water or milk.

The fact that Ang II always increases the intake of both milk and water highlights a methodological diffi-

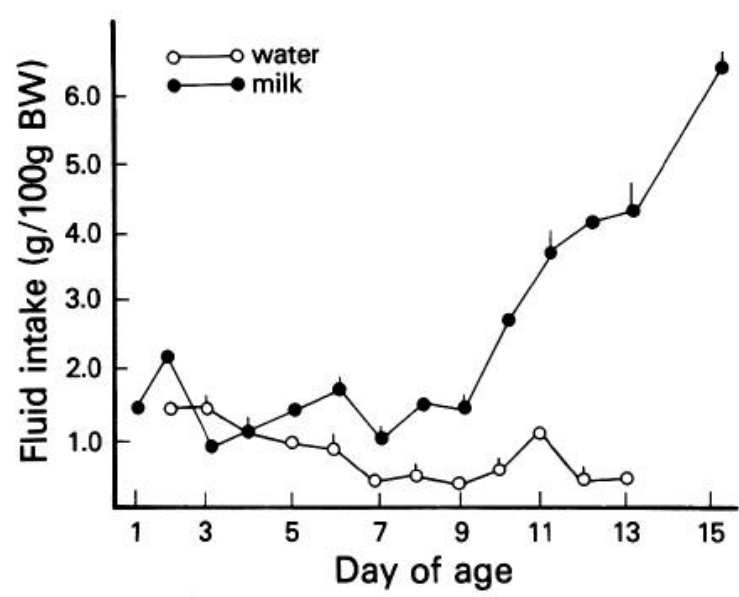

Figure 7. Untreated pups, taken directly from their dam, ingest small volumes of both milk and water until 7 days, at which age their milk intake increases to levels as high as $6 \%$ of body weight in 15-day-olds. Water intake remains low throughout.

culty inherent in these experiments. Unlike the adult, who can be offered a choice between solid, dry food and water, the suckling's "choice" is between two fluids. Although only one is nutritive, both are hydrating and can satisfy the thirsty pup. Consequently, we can assess only the relative effects of intracranial Ang II on food and water intake in the neonate. Again, as shown by this experiment, only the milk-sated, 8-day-old rat displays the adult-like response to Ang II, at which time it begins to ingest more water than milk. This occurs 5 to 6 days after the pup's initial, undifferentiated response to Ang II.

A distinction must also be drawn between the results of water and milk-sated pups based on the data shown in Figure 8. As the top panels of this figure illustrate, vehicle-injected rats consume very little water or milk after being milk-sated prior to injection. Hence, the 


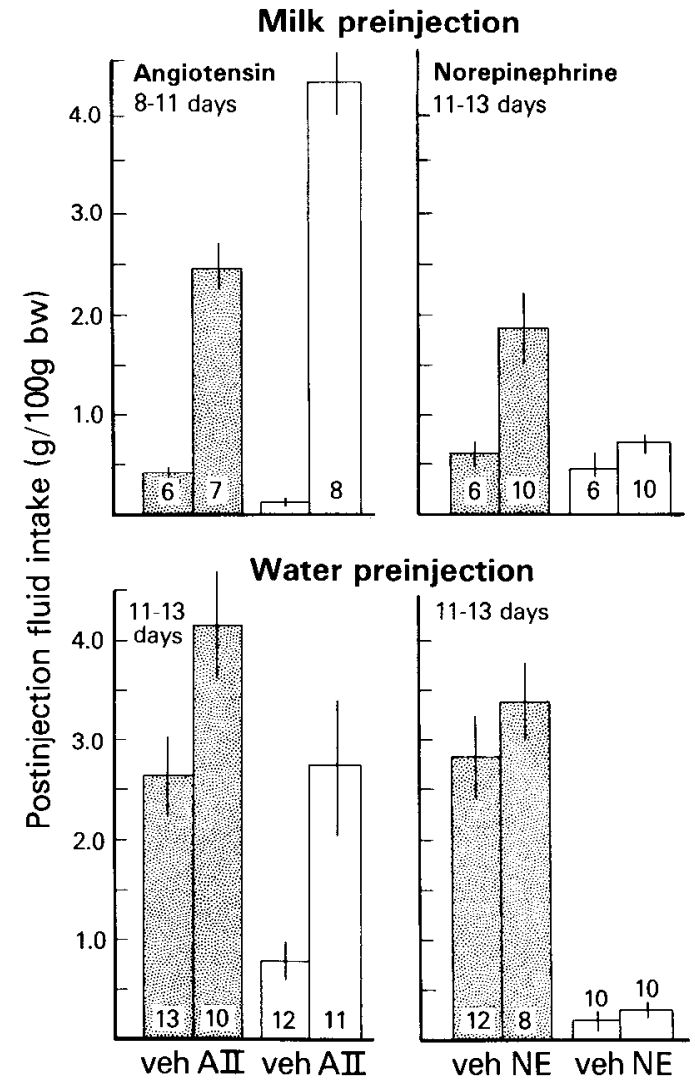

Figure 8. The upper panels show the effect on milk and water intake of ICV NE and of Ang II on milk and water intake of milk-sated pups. Again, stippled bars represent animals offered milk postinjection and open bars represent those that were offered water. Although Ang II augments both milk and water intake, pups drink twice as much water as milk. In contrast, NE increases milk intake only. The lower panels illustrate the effects of these agents on water-sated rats. Again NE never affects water intake. Ang II results are confounded by high intakes of milk in the ICV vehicle group.

increase in fluid ingestion by the milk-sated rat is due solely to injection with the neurochemical agent (e.g., Ang II or NE). Compare these data with those shown by pups offered water during the pre-injection ingestion period (lower panels). Note that when water-sated, the vehicle-injected animals, as well as the agent-injected animals, consume relatively large amounts of milk. This phenomenon can be explained by the "neonatal gluttony" discussed in the introduction to this experiment.

To reiterate, untreated pups beginning at 9 days of age ingest large amounts of milk. Therefore, when not first offered milk prior to injection, pups of these ages will drink milk whether injected with vehicle or agent, and, as seen in the lower panels of Figures 8 and 9, differential intake of milk or water that is due to ICV treatment with an agent is obscured by their high spontaneous intake of milk.

\section{Experiment IV: Effect of ICV NE on suckling}

The results of experiment III show that NE is capable of influencing intake when the pup is separated from its dam and allowed to ingest without the execution of suckling behavior. In order to test the hypothesis that suckling is not simply an immature form of adult ingestion, we examined the effect of ICV NE on milk intake when the pups were in the natural litter situation.

$\mathrm{NE}$ did not effect milk intake on the dam in 10 - to 12 day-old pups (NE main effect: $F(1,14)=1.30 ; p<0.60$ ). Neither did it effect latency to attach (vehicle, $27 \pm 10$; $\mathrm{NE}, 35.67 \pm 3.18)$ nor incidence of attachment to the nipple (vehicle, $5.67 \pm 1.35 ; \mathrm{NE}, 3.33 \pm 1.22$ ). The failure to observe any increase in milk ingestion was not due to a ceiling effect. Availability of mother's milk was not the limiting factor because, as Figure 10 shows, when pups at this age (10 to 12 days) were allowed to suckle without pre-ingestion of milk (no pre $R_{x}$ ), they ingested more than twice as much as when tested after milk pre-ingestion in imitation of the off-dam experiments in which the orexigenic effect of ICV NE was obvious (at far left in Fig. 10). The pups themselves are capable of greater intakes under our conditions of testing, as is shown by the 12-hr deprived group that ingested more than $9 \%$ of their body weight during the $2 \mathrm{hr}$ of access to their dam.

Therefore, NE does not influence the suckling behavior of pups that are already responsive to its orexigenic effects when they are feeding away from the dam.

\section{Discussion}

This work suggests answers to the several questions posed in the introduction. First, it tells us the postnatal

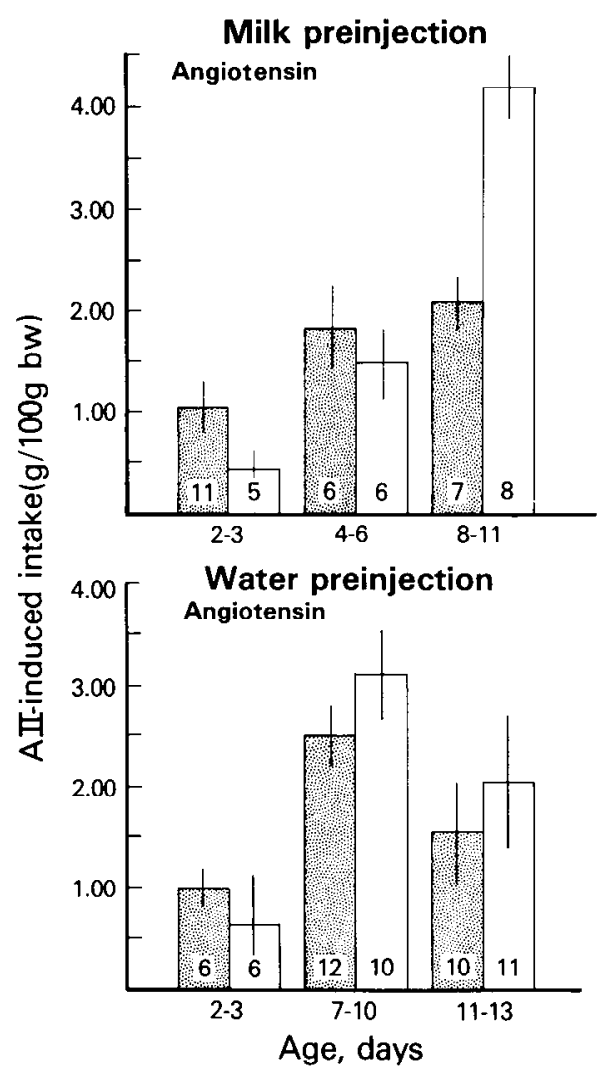

Figure 9. Development of the selective effect of Ang II on water intake. The upper panel shows that not until 8 days of age does Ang II differentially affect water drinking in the pup as it does in the adult. The lower panel again demonstrates the high milk intakes typical of both vehicle- and agent-treated pups who are not milk-sated prior to injection. 


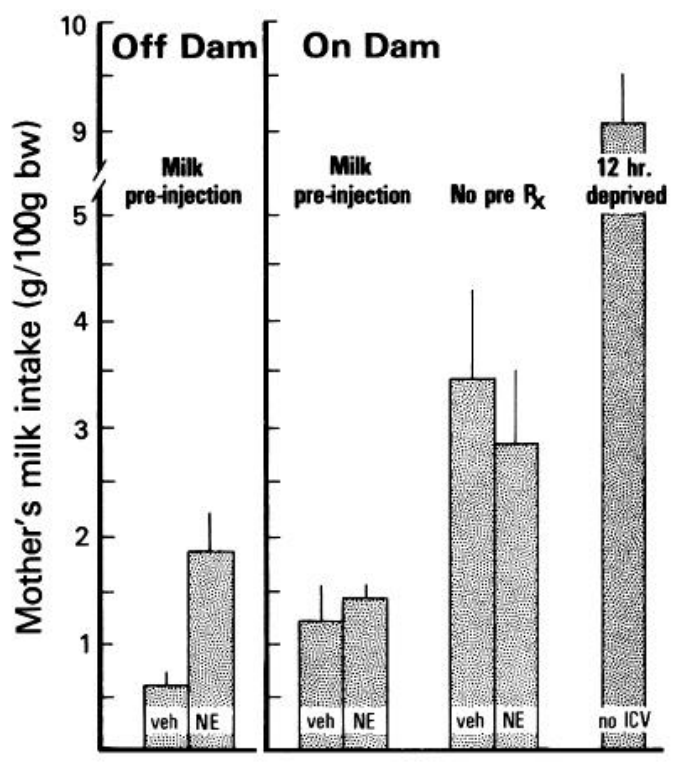

Figure 10. Right, Lack of effect of ICV NE on suckling. NE does not increase mother's milk intake of pups suckling from their dam, in pups that are sated on milk (Milk pre-injection) and in those that are not (No pre $R_{x}$ ). Twelve-hour deprived pups not treated with ICV NE ingest almost $9 \%$ of their body weight in milk from the dam in the 1-hr test, demonstrating that the lack of effect of NE in the other groups is not due to limited supply of mother's milk. Left, the orexigenic effect of ICV NE in pups off the dam for comparison. Same data as in Figure 8 (NE 11 to 13 days).

ages at which the rat brain first becomes responsive to the three agents studied. Despite our use of a test of neonatal drinking that is different from that used by Misantone et al. (1980), we have confirmed their report that 2-day-old rat pups drink in response to intracranial (ICV) Ang II and that a second stage of increased responsiveness occurs at the transition from 5 to 6 days. In reporting these phenomena, Misantone et al. pointed out that the response of the older pups is adult-like in sensitivity and potency because they drink to doses of ICV Ang II (1 ng) as low as the lowest reliable dose that is dipsogenic in the mature rat, and because, in proportion to body weight, they drink as much. Carb, on the other hand, does not affect drinking until 4 days of age with no further increase in its dipsogenic effect. In addition, it is not as potent on a molal basis as angiotensin. The orexigenic effect of norepinephrine (NE) appears at 9 and 10 days of age. At that age, and thereafter, a milksated pup will eat again after NE is deposited in its ventral third ventricle adjacent to the paraventricular nucleus which apparently contains the receptors that mediate its orexigenic effect (Leibowitz, 1978; Matthews et al., 1978).

Second, we (Misantone et al., 1980) have already shown by a dose-response study that the neural system for response to Ang II achieves adult sensitivity at 4 to 5 days of age. The dose-response studies reported here for Carb and NE were complicated by our decision to omit the India ink from the injection vehicle with a consequent loss of reliability in validation of the sites of our injections and by large interlitter variability in responsiveness to the agents. Nevertheless, we were able to show that shortly after the pups become responsive to each agent they drink or feed to doses that are similar to those that are used to elicit reliable ingestion from adult rats.

Third, this work shows the chronology of development of the characteristic adult response to each agent. That is, it reveals the sequence of behavioral changes with which Ang II and Carb become dipsogenic, and it shows how NE develops its characteristic orexigenic effect.

A mature, Ang II-injected rat will, when offered a choice, drink water rather than ingest food. In the case of the suckling, an "adult-like" response would be one in which it would consume water rather than milk (its food) when given ICV Ang II. Misantone et al. (1980), who did not satiate their pups for milk, found that 5-, 14-, and 21-day-old pups injected with Ang II drank as much milk as water when these fluids were offered via the water fountain. Only when the animals were weaned early ( 17 days) and then offered a choice between milk and water did they display the characteristic adult preference for water.

We have clarified this issue by permitting the pups to consume milk prior to injection. This reduced their avidity for it and allowed us to demonstrate that pups as young as 2 days of age drink in response to intracranial Ang II without differentiating between milk and water, then at 8 days postpartum they drink twice as much water as milk. The mechanisms for the dipsogenic response to Ang II, therefore, mature in two stages. The hormone acts first, and at a very early age, to increase ingestion of watery fluids whether they be water or milk. Then at 8 days of age the differential response to water appears, but it remains relative. Milk is still drunk but in a lesser volume. Clearly at this age neural maturation has proceeded to the stage at which water can be distinguished from milk and at which angiotensin arouses thirst, that is, the disposition to consume water in preference to nutritive fluids.

The development of Carb responsiveness is less complex. At 4 days it becomes dipsogenic when injected into the ventricles. Similarly, the chronology of the adult response to NE is simple. It has no effects on ingestion until the pup is 9 days old, at which age it becomes exclusively orexigenic.

And fourth, our demonstration of the increasing behavioral competence of the rat pup for ingestion as it advances in age, and of the different ages at which specific competences mature, suggests causal relations between the behaviors expressed by the animal and the ontogenies of the neurological systems for mediation of the effects of Ang II, Carb, and NE. Such relations must exist, and our work suggests what they may be.

The precocious drinking response of the suckling rat to Ang II corresponds to the early development of the subfornical organ (SFO) (Dellman, 1982), which mediates the dipsogenic actions of blood-borne Ang II in the adult rat (Simpson and Routtenberg, 1972). The SFO begins to differentiate at 17 days postconception and possesses the morphological characteristics of a functioning organ at 21 days. At 30 days postconception (8 to 9 days postnatal) it resembles that of the adult. Dellman (1982) points out that the rapid early postnatal, fine 
structural changes, e.g., protrusions of ependymal cells, differentiation of type I and II neurons, etc., parallel the increases in water consumption seen at 5 to 6 days by Misantone et al. (1980) and now by us. A second set of receptors mediating Ang II-induced thirst appears to lie in the nucleus medianus of the preoptic area (Lind and Johnson, 1982). Perhaps the two-stage onset of drinking to ICV Ang II seen in our pups (onset at 2 days, then increased effect at 5 to 6 days) is related to different maturation rates of these two receptor systems.

It is also of interest that the necessary components (renin, angiotensinogen, angiotensin-converting enzymc) of the renin-angiotensin system are differentiating in the perinatal period (Pohlova and Jelinek, 1974; Wallace et al., 1978; Wigger and Stalcup, 1978). In this same context, as Misantone et al. (1980) noted, consumatory responding to ICV Ang II is present just prior to the age at which drinking is induced by $\beta$-adrenergic activation with isoproterenol (Wirth and Epstein, 1976), a finding consistent with the suggestion that renin release from the kidney and enzymatic synthesis of Ang II mediate the drinking induced by this agent (Houpt and Epstein, 1971; Evered and Robinson, 1981).

Like Ang II, Carb is an effective dipsogen in the adult (Grossman, 1960) but, unlike Ang II, central arousal of drinking is associated almost exclusively with the rat. However, there is evidence that the SFO contains receptors upon which Carb, as well as Ang II, acts to elicit drinking (Simpson and Routtenberg, 1972; Phillips and Felix, 1976; Mangiapane and Simpson, 1978). But Carb does not effect drinking in the rat until after the onset of angiotensin responsiveness, and there is no further increase in water consumption at later ages. Therefore, if the SFO does indeed mediate the drinking response of both Ang II and Carb, then there are either two sets of receptors for these agents, each with a different developmental course, or else they act on the same set of receptors, but they are sensitive to each agent at a different time in their development.

In general, cholinergic postsynaptic receptors are near adult levels in the rat brain at birth and complete their development at different rates in different areas, although only a small fraction of the adult number of synapses has yet been formed (Rotter et al., 1979). Concentrations of $\mathrm{ACh}$ in the neonatal brain are approximately one-half adult levels (Mann et al., 1971), even though activity of choline acetyltransferase, its synthetic enzyme, has been reported to be only at $7 \%$ of adult activity (Ladinsky, et al., 1972). The varying rate of development of cholinergic receptors may account for the observation that behaviors known to be mediated by the cholinergic system appear at various times during the rat's development (see Smith et al., 1979). For example, cholinergic agonists do not induce the catalepsy seen in the adult until 15 days of age (Baez et al., 1976) nor do cholinergic antagonists produce the adult response of hyperactivity until 20 days, and Holmgren and Urba-Holmgren (1977) observed that cholinergic agonists produced stereotyped yawning and head shaking during the first and second weeks of life. More relevant to ingestive behavior, Spear and Ristine (1982) report a decrease in suckling with intracisternal injections of the cholinergic antagonist, scopolamine, in 3- to 4-day-old rats. This may be the behavioral counterpart of the cholinergic arousal of thirst reported here at a similar age. Taken together, these two reports suggest that mechanisms for behavioral responsiveness to cholinergic activation are present in the brain well in advance of a complete neurological system for acetylcholine's actions.

In contrast to the two dipsogens (Ang II and Carb), $\mathrm{NE}$ affects feeding behavior. Its orexigenic effect was first demonstrated in the adult rat by Grossman (1960), and subsequent work has shown that the most sensitive site of NE-induced eating is the paraventricular nucleus (PVN) of the anterior hypothalamus and that it is dependent upon $\alpha$-adrenergic receptor activation (Booth, 1968; Leibowitz, 1972). Reported effects on feeding include increased eating in the food-sated animal (Grossman, 1960) and/or increased meal size in the spontaneously ingesting rat (Ritter and Epstein, 1975).

Although the onset of the rat's response to $\mathrm{NE}$ is considerably later in its development than that for either Ang II or Carb, it is surprisingly precocious given the fact that the adrenergic system develops primarily after parturition. There is scarcity of noradrenergic terminals at birth which attain an adult pattern of density 2 to 3 weeks later in caudal regions and 4 to 5 weeks later more rostrally (Loizou, 1972). Specifically, catecholamine (CA) terminals are present in the PVN at birth but do not reach adult density until 3-4 weeks postpartum (Loizou, 1972). However, the three enzymes necessary for $\mathrm{NE}$ synthesis (tyrosine hydroxylase, dopa decarboxylase, and dopamine hydroxylase) are present in fetal rat brain at 15 days' gestation. Therefore, NE can be synthesized early in ontogenesis (Coyle, 1974). Again, as in the case of carbachol, behavioral effectiveness appears to precede the completion of neurochemical development.

The development of the $\alpha$-receptors that are believed to mediate the feeding response to $\mathrm{NE}$ is also mainly a postnatal event. Adrenergic receptors are already differentiated at birth into $\alpha_{1}$ - and $\alpha_{2}$-receptors, and their binding sites begin to increase at 9 to 10 days postpartum (Morris et al., 1980), which is when we observe the first orexigenic effects of NE. Moreover, Nomura and Segawa (1979) elicited locomotor hyperactivity in 7-day-old rats and locomotor hypoactivity in 20 -day-old rats by stimulating central $\alpha$-adrenergic receptors with clonidine. These receptors gradually mature, peaking at 3 weeks postpartum, at which time they regress to adult levels.

In summary, this survey of the ontogeny of neurochemical systems for angiotensin, carbachol and norepinephrine suggests that the elements mediating drinking in response to Ang II and Carb, as well as those for $\mathrm{NE}$-induced feeding, are behaviorally functional well before they have become anatomically and biochemically mature.

Lastly, several behavioral issues are raised by this work that bear on our understanding of the ontogeny of ingestion. One of these is the methodology for the study of water drinking in neonate rats. The earliest work on the development of drinking behavior was done in the weanling rat because methods for the study of water intake in the suckling had not yet been invented. In 1956, Krecek, 
Krecekova and Dlouha reported that rats weaned at day 14 onto cow's milk, solid food, and water drank more milk than water in response to a stomach load of hypertonic $\mathrm{NaCl}$. The selective adult response of water drinking did not appear until the end of the fourth week. Krecek and Krecekova (1957) went on to demonstrate that, if rats were weaned directly onto solid food and water, the dehydrated 19-day-old responded like an adult by drinking more water than milk. Fluids were offered in reservoirs at some distance from these immature animals and appetitive behaviors were, therefore, necessary before ingestion could occur.

Almli's (1973) technique for testing pups in their litter was the first for direct consumatory testing of the suckling rat. With it he showed that the pup would drink water in response to cellular dehydration at 14 days of age. He later demonstrated that (1) 56 to $88 \%$ of lateral hypothalamic neurons are osmosensitive between 8 and 21 days and that their basal firing rates increase with development, and (2) lateral preoptic damage at 10 days disrupts drinking to cellular dehydration in the adult.

In 1976 Wirth and Epstein devised their "water fountain" which permitted the study of water intake by pups of any age. They showed that pups as young as 2 days of age would drink water in response to cellular dehydration. Drinking to hypovolemia and renal renin release matured at 4 and 6 days, respectively. Bruno (1981) then offered either milk or water to dehydrated pups (ages 3 to 20 days) through an anterior oral catheter and found that they consumed equal amounts of both. Only when an appetitive requirement was introduced and when 20day-olds were studied did a selective intake of water appear. By requiring the dehydrated pup to drink from a cup placed some distance away, Bruno observed, as did Krecek and Krecekova (1957), the characteristic adult response to this challenge of increased water drinking and decreased milk drinking.

Misantone et al. (1980) also failed to elicit selective intake of water when pups were injected intracranially with Ang II and were then tested using the Wirth "water fountain." But pups that were weaned at 17 or 21 days and were tested in a two-choice appetitive test did ingest more water than milk (Misantone et al., 1980). In other words, they behaved like adult rats that drink water rather than ingest food in response to angiotensin or cellular dehydration.

Unlike the previous studies in which a selective intake of water was not clearly expressed by thirst-challenged rats until they were on the eve of weaning, the present study unmasked the suckling's ability to discriminate between water and milk when drinking is aroused by intracranial angiotensin. In addition to the pup's age at the time of testing, which is a factor of obvious importance, the success of this study hinged on our sensitivity to the state of satiation of the pups for milk. We found that untreated pups, taken immediately from their dam, are eager to ingest milk and that the amount that they will drink varies dramatically with age. For example, we discovered that while pups younger than 9 days consume $3 \%$ of their body weight during an hour-long period, pups of 15 days may consume up to $6 \%$ of their body weight. Wirth recognized the need to satiate pups prior to treatment and did so by depriving them of their dam and then allowing them access to her just before they were tested. We improved on this technique here by use of Hall's (1979) mouth catheter through which the pups could be fully satiated for milk (our "pre-injection ingestion period" with milk as the offered fluid). This reduced their subsequent milk intake and allowed us to demonstrate a differential dipsogenic effect of angiotensin at 8 days at age.

The pre-ingestion of milk also allowed us to demonstrate the selective orexigenic effect of norepinephrine in the 9- to 10-day-old pup and to show that the neonate is responsive to neurochemical manipulations of feeding as well as drinking behavior. There are several other recent studies of this problem. Raskin and Campbell (1981) report that amphetamine reduces milk intake of pups as young as 5 days of age but only when they are fed off the nipple. This is directly complementary to our work with $\mathrm{NE}$, but, because the amphetamine anorexia occurs earlier in development than the onset of NEinduced feeding, the two effects may not be mediated by the same adrenergic substrates. Last, recent work suggests that suckling can be suppressed by anticholinergic mechanisms early in the neonate's career (Spear and Ristine, 1982) and can then be disinhibited by serotonin blockers at the time of weaning (Williams et al., 1979).

The results reported here also bear on a theoretical issue that emerges from recent work which shows that suckling behavior, which must be done while pups are on a nipple, and ingestive behavior, which they do while they are off the nipple, are not affected in the same way in pups treated in the same manner. For instance, in contrast to their findings in pups ingesting while off the nipple, Raskin and Campbell (1981) found that amphetamine does not reduce milk intake from the nipple until the pups are 15 days old. In addition, gastric distention, which reduces food intake in the adult, also reduces milk intake by the suckling pup beginning at 1 day of age (Lorenz et al., 1982), but the same treatment does not affect the latency with which pups approach a dam and attach to a nipple until 11 to 12 days postpartum (Hall and Rosenblatt, 1977).

When we tested NE in the suckling situation, we found another difference of this kind. At an age (9 to 10 days or older) when it was orexigenic in pups feeding away from their dam, NE had no effects on nipple attachment latencies or on the amount of time spent on the nipple. Moreover, it had no effect on milk intake when pups suckled from their dam. Therefore, despite its maturation during the suckling period, the neurological mechanism for the noradrenergic control of feeding appears to be a nascent neurochemical system for control of subsequent adult feeding rather than a functioning control of ongoing suckling. This interpretation is consistent with the current view that feeding and drinking, on the one hand, and suckling, on the other, are controlled by neurological systems that follow separate and parallel paths of development (see Blass et al., 1979 and Hall and Williams, 1983 for reviews).

\section{References}

Almli, C. R. (1973) The ontogeny of the onset of drinking and plasma osmotic pressure regulation. Dev. Psychobiol. 6: 147158 . 
Babicky, A., J. Ostadaloco, J. Parizek, R. Kalar, and B. Bibr (1973). Onset and duration of the physiological weaning period for infant rats. Physiol. Bohemoslov. 22: 449-456.

Baez, L. A., N. K. Eskridge, and R. Schein (1976). Postnatal development of dopaminergic and cholinergic catalepsy in the rat. Eur. J. Pharmacol. 36: 155-162.

Blass, E. M., and C. P. Cramer (1982) Analogy and homology in the development of ingestive behavior. In Changing Concepts of the Nervous System, A. R. Morrison and P. L. Strick, eds., pp. 503-524, Academic Press, Inc., New York.

Blass, E. M., W. G. Hall, and M. S. Teicher (1979) The ontogeny of suckling and ingestive behaviors. Prog. Psychobiol. Physiol. Psychol. 8: 243-299.

Booth, D. A. (1968) Mechanism of action of norepinephrine in eliciting an eating response on injection into the rat hypothalamus. J. Pharmacol. Exp. Ther. 160: 336-348.

Bruno, J. P. (1981) Development of drinking behavior in preweanling rats. J. Comp. Physiol. Psychol. 95: 1016-1027.

Coyle, J. T. (1974) Development of the central catecholaminergic neurons. In Neurosciences, Third Study Program, F. O. Schmitt and F. G. Worden, eds., pp. 877-884, MIT Press, Cambridge, MA.

Dellman, H. D. 91982) Recent advances in subfornical organ morphology. I. Fine structure of the rat subfornical organ during prenatal and early postnatal development. In Cerebrospinal Fluid and Peptide Hormones, F. M. Rodriguez and T. B. van Wimersma Greidanus, eds., pp. 68-78, S. Karger AG, Basel.

Evered, M. D., and M. M. Robinson (1981) The renin-angiotensin system in drinking and cardiovascular responses to isoprenaline in the rat. J. Physiol. (Lond.) 316: 357-367.

Grossman, S. P. (1960) Eating and drinking elicited by direct adrenergic or cholinergic stimulation of the hypothalamus. Science 132: 301-302.

Hall, W. G. (1979) The ontogeny of feeding in rats. I. Ingestive and behavioral responses to oral infusions. J. Comp. Physiol. Psychol. 93: 977-1000.

Hall, W. G., and J. S. Rosenblatt (1977) Suckling behavior and intake control in the developing rat pup. J. Comp. Physiol. Psychol. 91: 1232-1247.

Hall, W. G., and C. L. Williams (1983) Suckling isn't feeding, or is it? $\Lambda$ search for developmental continuities. In Advances in the Study of Behavior, J. Rosenblatt, ed., pp. 218-254, Academic Press, Inc., New York.

Holmgren, B., and R. Urba-Holmgren (1977) Cholinergic mechanisms involved in head-shaking of infant rats. Pharmacol. Biochem. Behav. 7: 193-199.

Houpt, K. A., and A. N. Epstein (1971) The complete dependence of beta-adrenergic drinking on the renal dipsogen. Physiol. Behav. 7: 897-902.

Houpt, K. A., and A. N. Epstein (1973) Ontogeny of controls of food intake in the rat. G. I. fill and glucoprivation. Am. J. Physiol. 225: 58-66.

Krecek, J., and J. Krecekova (1957) The development of the regulation of water metabolism. III. The relation between water and milk intake in infant rats. Physiol. Bohemoslov. 6: $26-34$

Ladinsky, H., S. Consolo, G. Peri, and S. Garattini (1972) Acetylcholine, choline and choline acetyltransferase activity in the developing brain of normal and hypothyroid rats. $J$ Neurochem. 19: 1947-1952.

Leibowitz, S. F. (1972) Central adrenergic receptors and the regulation of hunger and thirst. Res. Publ. Assoc. Res. Nerv. Ment. Dis. 50: 327-358.

Leibowitz, S. F. (1978) Paraventricular nucleus: A primary site mediating adrenergic stimulation of feeding and drinking. Pharmacol. Biochem. Behav. 8: 163-175.
Lind, R. W., and A. K. Johnson (1982) Central and peripheral mechanisms mediating angiotensin-induced drinking. In The Renin Angiotensin System in the Brain, D. Ganten, M. Printz, M. I. Phillips, and B. A. Scholkens, eds., pp. 353-364, Springer-Verlag, Heidelberg.

Loizou, L. A. (1972) The postnatal ontogeny of monoaminecontaining neurons in the central nervous system of the albino rat. Brain Res. 40: 395-418.

Lorenz, D. N., S. B. Ellis, and A. N. Epstein (1982) Differential effects of upper gastrointestinal fill on milk ingestion and nipple attachment in the suckling rat. Dev. Psychobiol. 15 $309-330$

Mangiapane, M. L., and J. B. Simpson (1978) Subfornical organ: Site of pressor and drinking actions of acetylcholine. Soc. Neurosci. Abstr. 4: 547.

Mann, E., O. Pleul, and H. Kewitz (1971). Free and structurally bound acetylcholine in the developing rat brain. NaunynSchmiedeberg's Arch. Pharmacol. 269A: 473.

Matthews, J. W., D. A. Booth, and I. P. Stolerman (1978) Factors influencing feeding elicited by intracranial noradrenaline in rats. Brain Res. 141: 119-128.

Misantone, L., S. B. Ellis, and A. N. Epstein (1980) Development of angiotensin induced drinking in the rat. Brain Res. 186: $195-202$

Morris, M. J., J. P. Dausse, M. A. Devynch, and P. Meyer (1980) Ontogeny of and $\alpha$-adrenoceptors in rat brain. Brain Res. 190: 268-271.

Nomura, Y., and T. Segawa (1979) The effect of $\alpha$-adrenoceptor antagonists and metiamide on clonidine-induced locomotor stimulation in the infant rat. Br. J. Pharmacol. 66: 531-535.

Phillips, M. I., and D. Felix (1976) Specific angiotensin II receptive neurons in cat subfornical organ. Brain Res. 109: 531-540.

Pohlova, I., and J. Jelinek (1974) Components of the reninangiotensin system in rat during development. Pflugers Arch. 351: 259-270.

Raskin, L. A., and B. A. Campbell (1981) Ontogeny of amphetamine anorexia in rats: A behavioral analysis. J. Comp. Physiol. Psychol. 95: 425-435.

Ritter, R. C., and A. N. Epstein (1975) Control of meal size by central noradrenergic action. Proc. Natl. Acad. Sci. U. S. A. 72: $3740-3743$

Rotter, A., P. M. Field, and G. Raisman (1979) Muscarinic receptors in the central nervous system of the rat. III. Postnatal development of binding of $\left[{ }^{3} \mathrm{H}\right]$ propylbenzylcholine mustard. Brain Res. Rev. 1: 185-205.

Simpson, J. B., and A. Routtenberg (1972) The subfornical organ and carbachol-induced drinking. Brain Res. 45: 135157.

Smith, G. J., L. P. Spear, and N. E. Spear (1979) Ontogeny of cholinergic mediation of behaviors in the rat. J. Comp. Physiol. Psychol. 93: 636-647.

Spear, L. P., and L. A. Ristine (1982) Suckling behavior in neonatal rats: Psycho-pharmacological investigations. J. Comp. Physiol. Psychol. 96: 244-255.

Wallace, K. B., M. K. Bailie, and J. B. Hook (1978) Angiotensin converting enzyme in developing lung and kidney. Am. J. Physiol. 234: R141-R145.

Wigger, H. J., and S. A. Stalcup (1978) Distribution and development of angiotensin converting enzyme in the fetal and newborn rabbit. Lab. Invest. 38: 581-585.

Williams, C. I., J. S. Rosenblatt, and W. G. Hall (1979) Inhibition of suckling in weaning-age rats: A possible serotonergic mechanism. J. Comp. Physiol. Psychol. 93: 414-429.

Wirth, J. B., and A. N. Epstein (1976) Ontogeny of thirst in the infant rat. Am. J. Physiol. 320: 188-198. 